\title{
Fear, Stress and Stigma of Covid-19 among Indian Dental Practitioners
}

\author{
Ruchika Bagde ${ }^{1}$, Shilpa Dandekeri ${ }^{2}$ \\ 1, 2 Department of Prosthodontics and Crown \& Bridge, Nitte (Deemed to Be University), \\ AB Shetty Memorial Institute of Dental Sciences, Mangalore, Karnataka, India.
}

\section{ABSTRACT}

\section{BACKGROUND}

Novel coronavirus pandemic has impacted the lives and well-being of all people around the globe. Dental practitioners are at a high risk of catching infection. This situation has brought risk of death from infection along with unbearable psychological pressure. Therefore, this study was done to assess the impact of Covid-19 pandemic on mental health of dental practitioners.

\section{METHODS}

A survey was conducted amongst 265 dental practitioners using snowball sampling technique, collecting basic demographic data, practice setting and relevant data. Psychological stress was collected through Covid-19 Peri-traumatic Distress Index (CPDI). General self-efficacy scale (GSE) was used to measure the self-efficacy of dental surgeons. Pearson correlation between the distress levels and self-efficacy scores were calculated.

\section{RESULTS}

Nearly $3.7 \%$ respondent's score was indicative of low distress. $30.18 \%$ of the respondents' scores suggested moderate distress, and $65.6 \%$ of the respondents' scores were indicating severe distress. Mean self-efficacy was found out to be 22.06 (standard deviation $=4.71$ ). Those with greater self-efficacy scores reported less distress, showing a moderate negative correlation, with a Pearson coefficient of 0.1406 , which was statistically significant $(\mathrm{P}<0.02)$.

\section{CONCLUSIONS}

This study interprets the relationship between factors associated with Covid-19 and elevated psychological distress among dentists. There was a negative correlation between distress and self-efficacy of dentists. Stressors such as greater risk of infection for dentists, lockdown, falling economy and liabilities, social media, lead to anxiety, fear, and strong emotions. Dentists should be provided with broader understanding of mental health and the methods for enhancing the self-efficacy of dentists should be implemented. Professional help can be provided by the government to health workers for their mental well-being. Tele dentistry can be practiced in the pandemic to minimize the risk of infection.

\section{KEY WORDS}

Novel coronavirus, Dental Practitioners, Psychological Stress, Stressors, Economy
Corresponding Author: Dr. Shilpa Dandekeri, Department of Prosthodontics and Crown \& Bridge, Nitte (Deemed to be University), AB Shetty Memorial Institute of Dental Sciences, Mangalore, Karnataka, India. E-mail: drshilpadandekeri@nitte.edu.in

DOI: $10.14260 / j e m d s / 2021 / 498$

How to Cite This Article:

Bagde R, Dandekeri S. Fear, stress and stigma of covid-19 among Indian dental practitioners. J Evolution Med Dent Sci 2021;10(31):2433-2438, DOI: $10.14260 /$ jemds/2021/498

Submission 28-11-2020,

Peer Review 29-05-2021,

Acceptance 05-06-2021,

Published 02-08-2021.

Copyright (C) 2021 Ruchika Bagde et al This is an open access article distributed under Creative Commons Attribution License [Attribution 4.0 International (CC $B Y 4.0)]$ 


\section{BACKGROUND}

In December 2019, the coronavirus (Covid-19) outburst occurred in China. ${ }^{1}$ In a while, the entire world was in the grasp of the coronavirus and World Health Organization (WHO) professed on 11 March 2020 that it was a pandemic. The world has witnessed an exponential growth in rising infections and deaths since then. The coronavirus has affected 213 countries and territories around the world. Nearly $163,964,242$ people are confirmed to be affected by the virus as on May 17, 2021 around the globe.

The pathogen responsible for the coronavirus disease is severe acute respiratory syndrome coronavirus 2 (SARS-CoV2). It can be transmitted from human-to-human primarily via respiratory droplets. ${ }^{2}$ In response to the spread of the novel coronavirus, lockdown had been imposed by almost all the countries. The Government of India imposed a nationwide lockdown on 24 March 2020, and in turn confined the entire population as a precautionary measure against the Covid-19 pandemic in India. ${ }^{3}$

Similarly, the SARS outbreak of 2002 - 2004 was an epidemic during which people from over 29 different countries and territories were infected. ${ }^{4}$ Fear of SARS rose from basic anxiety of a disease with an unknown cause and likely fatal outcome. ${ }^{5}$ Studies disclosed that around $18 \%-57$ $\%$ of healthcare workers suffered significant emotional distress.6,7 Additionally, medical professionals were infected despite the protective measures. ${ }^{8}$

As mentioned earlier, SARS-CoV-2 spreads via respiratory droplets, therefore dental personnel may be exposed to the virus. ${ }^{9}$ In practice, probable routes of transmission of virus include airborne spread by means of aerosols, contact with the person, and soiled surface spread.9,10 On 17 March, the Dental Council of India suggested that the country's dental fraternity suspend all non-essential or non-urgent services.
Meticulous infection control protocols were followed while providing treatments for dental emergencies. ${ }^{11}$ Despite following universal precautions, the spread of the virus seemed higher when treatment was provided to an infected patient or a carrier. ${ }^{12}$ Lot of deaths are reported worldwide due to novel coronavirus. A recent study shows that in noncoronavirus deaths reported, suicide was the primary cause, due to distress caused by the nationwide lockdown. According to the data, the main causes were loneliness, fear of contracting the virus causing Covid-19, and financial distress. ${ }^{13}$ According to a recent survey, most of the participants were constantly thinking about the pandemic, few of them faced difficulty in getting a sound sleep, others were fearful of catching the infection, and most were distressed. There was a perceived mental healthcare need in at least $80 \%$ of the participants. ${ }^{14}$ Dentists around the globe are also in a state of distress and fear whilst working in their respective fields due to Covid- 19.15 With the announcement of unlocking of the economy and most services resuming; dental practitioners all over India are gearing up to resume their services after following the 70 days nationwide lockdown. Thus, this study intended at evaluating the fear and stigma associated with Covid-19 among Indian dental practitioners as they resume their services and understand the factors associated with the same.

\section{METHODS}

On 31st May 2020, Central Government released guidelines on phase 5 of lockdown and India entered into phase1of unlock process. An online survey was conducted all over India from $01 / 06 / 2020$ to $10 / 06 / 2020$ for evaluating the psychological distress, self-efficacy according to the demographics amongst Indian dentists.

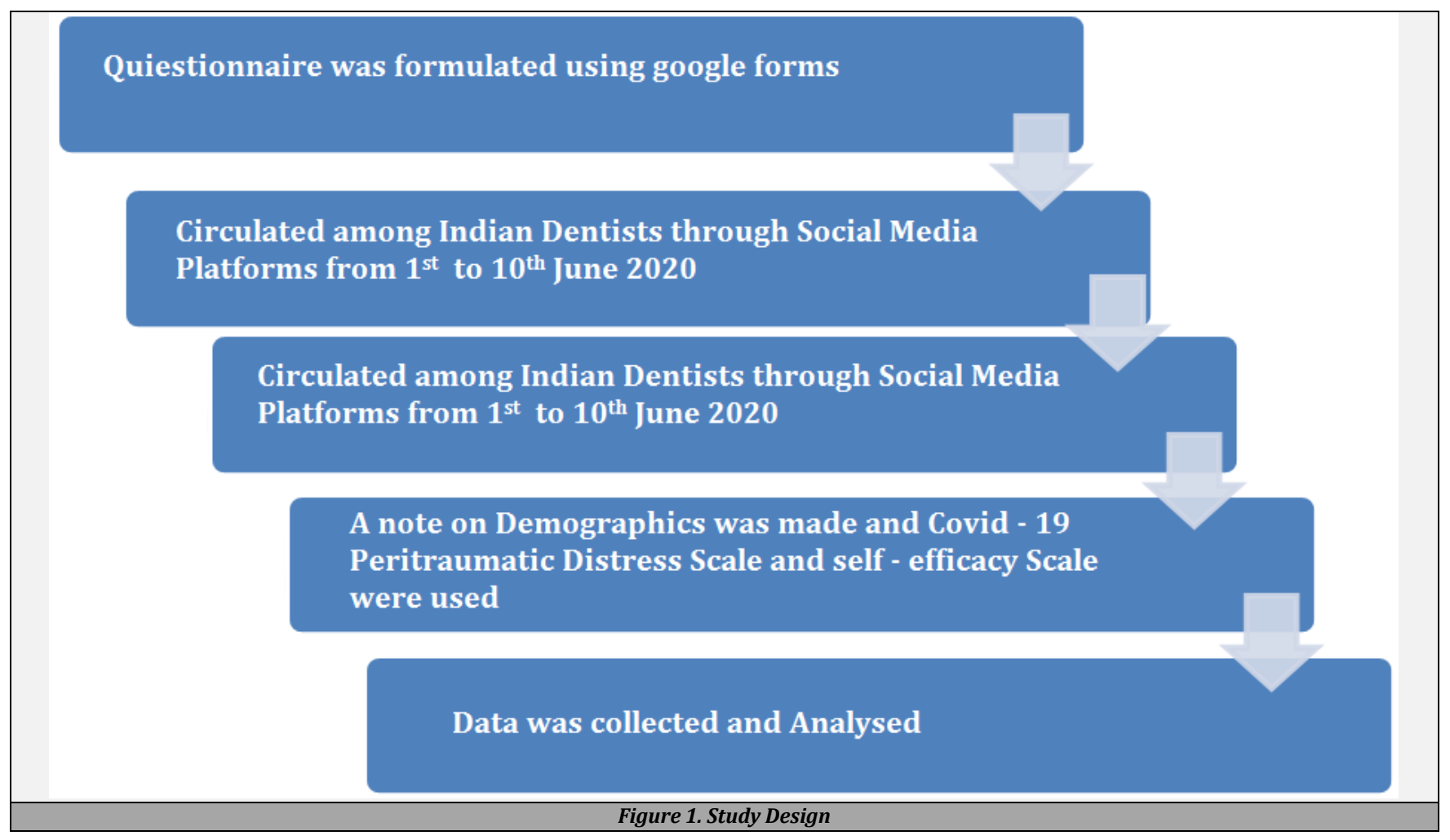




\section{Data Collection}

A questionnaire was formulated using Google forms in English which was circulated among Indian dentists using the snowball-sampling technique throughout social media forums. No personal identification, such as names, IP address, email IDs, were recorded. The basic information on the gender, age group (less than 25, 25 to 35,36 to 45,45 and above), state of practice along with the highest academic degree of the dentist (Bachelors in Dental Surgery, Masters in Dental Surgery, Doctor of Philosophy),dental practice setting (solo practice; corporate services; private solo practice with consultations; consultations exclusively; teaching and private practice and monthly income (less than 20,000, 2000150000, 50001-100000, more than 1 lakh Indian Rupees) were recorded. This self-designed survey utilized 2 previously validated questionnaires - Covid-19 Peritraumatic Distress Index (CPDI) and Self Efficacy and was validated by two specialists in the field. ${ }^{16,17}$

The Covid-19 Peritraumatic Distress Index CPDI scale consists of 20 questions; used to measure quantitatively the rate of recurrence of anxiety, explicit phobias, depression, physical symptoms, loss of social functioning, avoidance, and compulsive behaviour on a scale from 0 to $100 .{ }^{16}$ Self-efficacy influences the actions on basis of how individuals feel. It is assessed using General Self-Efficacy Scale.17 This scale is questionnaire based containing 10 items, for which the answers are marked on a Likert scale extending from 1 for "Strongly disagree" to 4 depicting "Strongly agree". Low selfefficacy is related to anxiety, depression, and a feeling of helplessness. And people with a high self-efficacy can accomplish more challenging tasks. ${ }^{18}$

Pearson correlation between the distress levels and selfefficacy scores were calculated. The data obtained was entered and analysed using Microsoft Excel. The data obtained from the Likert scale was evaluated and classified as low ( $<=27$ ), moderate $(>=28-51$ ) and severe $(>52)$. The mean and standard deviation of Covid-19 Peritraumatic Distress Index (CPDI) scores were calculated. The selfefficacy of dentists was calculated by finding the sum of all the answers. Similarly, mean, and standard deviation were calculated. Pearson's correlation coefficient was calculated to measure the strength of association between the two variables.

\section{RESULTS}

This study collected a total of 265 responses from all over India. Table 1 contains the list of demographic characteristics of the sample. The mean age of the study participants was 35.23 (Standard Deviation: 14.96) years. The mean (SD) CPDI score was 29.8 (8.88). Nearly $3.7 \%$ respondent's score was indicative of low distress. $30.18 \%$ of the respondents' scores suggested moderate distress, and $65.6 \%$ of the respondents' scores were indicating severe distress. (Table 2). Around 63 $\%$ of dentists were afraid of getting infected by the virus because of their profession. (Figure 2) $63.8 \%$ of dentists' feared of getting infection from the patients during the treatment (Figure 3 ) and $47.2 \%$ through auxiliary staff and co-workers. $74 \%$ of dentists' feared risking their relatives and friends to coronavirus. (Figure 4) Around $65 \%$ of dentists felt that Covid-19 had affected their financial status (Figure 5) and only $32.3 \%$ were practicing dentistry because of financial liabilities.

\begin{tabular}{|c|c|c|c|}
\hline \multicolumn{2}{|c|}{ Demography } & \multicolumn{2}{|c|}{$\begin{array}{l}\text { No. of Percentage } \\
\text { Dentists of Dentists }\end{array}$} \\
\hline \multirow{4}{*}{ Age } & 18 - 25 years & 40 & 15.1 \\
\hline & 26 - 40 years & 166 & 62.6 \\
\hline & $41-60$ years & 56 & 21.1 \\
\hline & above 60 years & 3 & 1.1 \\
\hline \multirow{2}{*}{ Gender } & Male & 73 & 27.5 \\
\hline & Female & 192 & 72.5 \\
\hline \multirow{13}{*}{ Region } & Maharashtra & 72 & 27.1 \\
\hline & Karnataka & 139 & 52.4 \\
\hline & West Bengal & 11 & 4.1 \\
\hline & Andhra Pradesh & 8 & 3 \\
\hline & Goa & 2 & 0.7 \\
\hline & Chhattisgarh & 2 & 0.7 \\
\hline & Kerala & 19 & 7.1 \\
\hline & Delhi & 2 & 0.7 \\
\hline & Rajasthan & 1 & 0.3 \\
\hline & Tamil Nadu & 4 & 1.5 \\
\hline & Gujarat & 1 & 0.3 \\
\hline & Haryana & 3 & 1.1 \\
\hline & Uttar Pradesh & 1 & 0.3 \\
\hline \multirow{3}{*}{$\begin{array}{l}\text { Highest Academic } \\
\text { Degree }\end{array}$} & BDS & 126 & 47.5 \\
\hline & MDS & 132 & 49.8 \\
\hline & $\mathrm{PhD}$ & 7 & 2.6 \\
\hline \multirow{5}{*}{ Practice Setting } & Private practice & 114 & 43 \\
\hline & Corporate services & 19 & 7.2 \\
\hline & Private practice with consultations & 47 & 17.7 \\
\hline & Consultations only & 19 & 7.2 \\
\hline & Teaching and private practice & 66 & 24.9 \\
\hline \multirow{4}{*}{ Monthly Income } & less than 20,000 INR & 69 & 26 \\
\hline & $20.001-50,000$ INR & 64 & 24.2 \\
\hline & $50,001-1,00,000$ INR & 84 & 31.7 \\
\hline & More than 1 lakh INR & 48 & 18.1 \\
\hline \multirow{3}{*}{$\begin{array}{l}\text { High risk for } \\
\text { Covid-19 }\end{array}$} & Yes & 15 & 5.7 \\
\hline & No & 246 & 92.8 \\
\hline & Don't know & 6 & 2.3 \\
\hline \multirow{3}{*}{$\begin{array}{l}\text { Practicing Dentistry } \\
\text { amidst Lockdown }\end{array}$} & Yes & 28 & 10.6 \\
\hline & No & 157 & 59.2 \\
\hline & Emergency cases only & 80 & 30.2 \\
\hline \multicolumn{4}{|c|}{$\begin{array}{l}\text { Table 1. Contains the List of Demographic } \\
\text { Characteristics of the Sample }\end{array}$} \\
\hline
\end{tabular}

\begin{tabular}{|cccc|}
\hline CPDI* & $\begin{array}{c}\text { Count } \\
(\mathbf{N})\end{array}$ & $\begin{array}{c}\text { Mean of } \\
\text { CPDI }\end{array}$ & $\begin{array}{c}\text { Standard } \\
\text { Deviation of CPDI }\end{array}$ \\
\hline Low distress $(<=27$ & 10 & 9.10 & 4.90 \\
Moderate distress $(>27<=51)$ & 81 & 21.51 & 3.12 \\
Severe distress $(>=52)$ & 174 & 34.88 & 5.64 \\
\hline Table 2. The Respondents' Scores Were Indicating Severe Distress \\
\hline CPDI*- Covid-19 Peritraumatic Distress Index \\
\hline
\end{tabular}

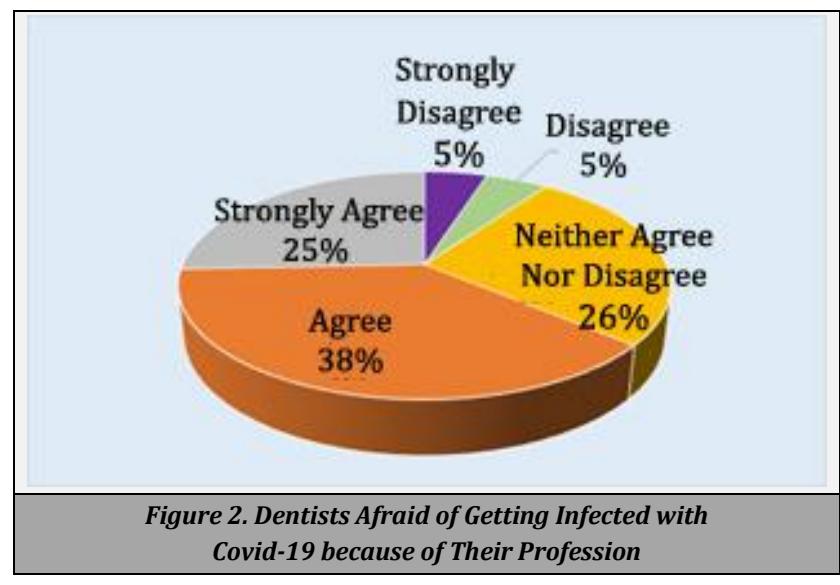

$60.8 \%$ of dentists felt helpless that they could not treat patients because of the pandemic and only $19.3 \%$ felt ashamed of their emotional reactions. $61 \%$ of dentists felt of having acquired enough knowledge concerning maintaining a safe working environment in response to the outbreak, but 
$41.9 \%$ of dentists were afraid to resume their services despite the precautionary guidelines provided. $39.7 \%$ of dentists believed that watching news related to Covid-19 made them anxious. Only $20.3 \%$ of dentists were considering a career change due to pandemic.
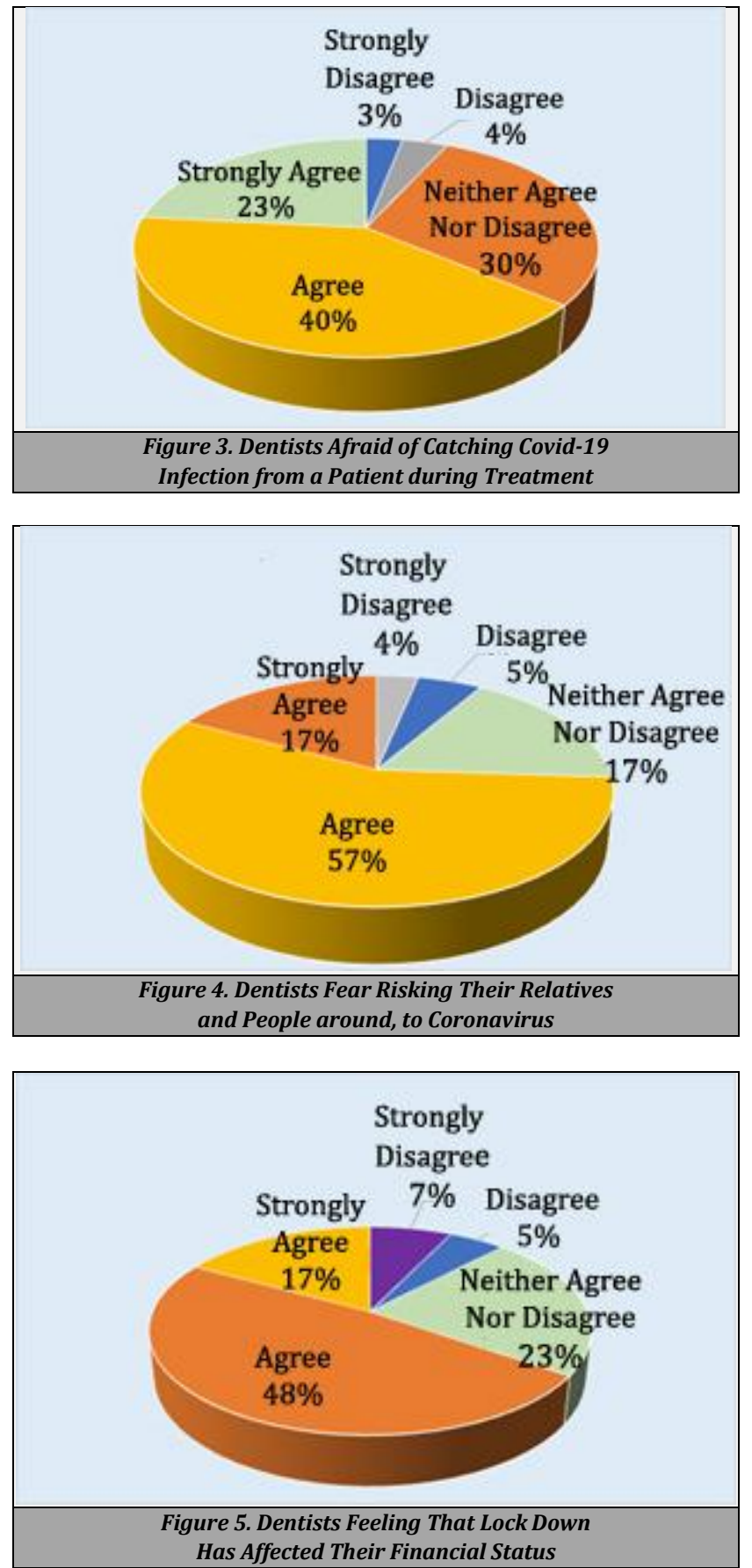

The self-efficacy of dentists was calculated by finding the sum of all answers. The total score varies between 5 and 30, with a higher score indicative of more self-efficacy. Mean selfefficacy was found out to be 22.06 (standard deviation = 4.71). Those with scores at the higher end reported less distress, presenting a moderate negative correlation, with a Pearson coefficient of -0.1406 , which was statistically significant $(\mathrm{P}<0.02)$.

\section{DISCUSSION}

Pandemics are wide ranging outbreaks of infectious disease that may result in a significant increase in morbidity and mortality over a wide geographic area, hence causing noteworthy disruption. They have been reported to cause significant individual behavioural changes. ${ }^{19}$ Covid-19 pandemic has caused a lot of uncertainty and this in turn, is related to depression and anxiety. ${ }^{20}$ Mental health problems have been documented among health care workers in the Covid-19 pandemic situation.21,22 Throughout the world, medical personnels are facing constant stress during their daily work, which involves increased risk of infection, exhaustion, social isolation, and being apart from their families. During the initial phase of the Covid-19 pandemic, a significant proportion of dentists have had a psychological impact during the crisis. ${ }^{23}$ Globally, significant disruptions have been caused due to restrictions like lockdown and social distancing, extending from individuals to families, communities, and whole countries. ${ }^{24}$ This changed mental health status resulting from the disturbance in the routine.

Many cases of Covid-19 related suicides have been stated in several countries. People with psychiatric disorders, residents of red zone areas, and people who have a witnessed death of a family member or a friend because of the virus are vulnerable. Also, survivors of the disease are not safe. ${ }^{25}$ Similarly, the effect of mental stress, fear, and anxiety leads the healthcare professionals and dentists to make irrational decisions and poor treatment outcome. ${ }^{26,27}$.

This study gathered a total of 265 responses from all over India. Amongst these, $72.6 \%$ were women and $27.4 \%$ were men, this is congruent with the fact that the number of female dentists is higher in India in comparison to males. ${ }^{28}$ In a similar study out of 52,730 valid responses, approximately 18,598 were males and 34,132 were females.

The mean (SD) CPDI score of the sample was 29.8 (8.88) and $65.6 \%$ of the respondents' scores were indicating severe distress. In the study 166 dentists (62.4\%) belonged to the age group 26 - 40 years. Similarly, in previous studies depression, anxiety and psychological distress showed a decline across age groups. Few of the age differences were accounted for negative social relationships and recent crises at work. ${ }^{29}$ Also, as the age advances, there is a likelihood of obtaining financial security and therefore the anxiety might be less. Meanwhile, as the young individuals are in the process of obtaining financial stability; they might be facing more stress.

Many dentists believe that the pandemic and lockdown have affected their financial status. While $59 \%$ of dentists were not practicing dentistry in the lockdown; $22.2 \%$ of dentists were practicing to fulfil the liabilities. Nationwide lockdown resulted in the shutting down of private clinics affecting the number of patients seeking dental service in turn disturbing the economy. Based on a study conducted in China during the rise of Covid-19, coronavirus influenced the dental services availed by people. The patients reporting to emergency saw a decline by $38 \%$ and other cases decreased by a rate of three out of ten. ${ }^{30}$

Although $61 \%$ of dentists believed that they have received enough information on maintaining a safe working environment in response to the Covid-19 outbreak, $41.9 \%$ 
were afraid to resume the services. Dentists were anxious about getting infected with Covid-19 because of the profession and the majority of them were afraid to catch Covid-19 infection from a patient during treatment, or via auxiliary staff and co-workers. $74 \%$ of dentists' feared risking their relatives and friends to coronavirus. This may be because coronavirus can be transmitted through contact with oral fluids and blood; inhalation; contact with the mucosa of the oral, orbital and nasal cavities; and through indirect interaction with soiled surfaces. ${ }^{2}$ The results also showed that dentists with a higher score for self-efficacy had a lower score for lower psychological distress. Undeniably, self-efficacy plays an important role in stressful situations, as it can help to increase one's performance in different occupational tasks. ${ }^{18}$

Furthermore, in general it acts as a moderator for the interconnection between psychopathological symptoms and well-being. ${ }^{31}$ One of the reasons may be the Conservation of Resources (COR) theory. It states that people after dealing with stressful situations retain resources. ${ }^{32,33}$ People with greater self-efficacy achieve success in handling stressful situations and their effects in the future conversely, low selfefficacy is connected with feeling of feebleness, nervousness, and depression. Similarly, in this article it was observed that the threat of loss of financial resources, valued objects and people compounded the distress.

\section{CONCLUSIONS}

Overall, this study interprets the relationship between factors associated with Covid-19 and elevated psychological distress among dentists. Stressors such as the greater risk of infection for dentists, lockdown, falling economy and liabilities, social media lead to anxiety, fear, and strong emotions. ${ }^{16}$ Our results depict that psychological distress and self-efficacy are inversely related; dentists with low self-efficacy have a higher level of distress. Thus, dentists of all should be provided with a comprehensive understanding of mental health and the methods for enhancing the self-efficacy should be implemented. Professional help can be provided by the government to health workers for their mental well-being. Tele dentistry can be practiced in the pandemic to minimize the risk of infection.

\section{Limitations}

It included short time of study sampling. Other being a small sample size which was surveyed, for a better understanding of the problem as the study should be conducted with a larger sample size and in a broader coverage area. Also, the participants were selected through social media and thus the study was likely to have selection bias. Also, dentists with government jobs were not listed separately. Dentists also faced problems in commuting to their workplaces because of lack of government transport facilities, which was not considered in the survey.

Data sharing statement provided by the authors is available with the full text of this article at jemds.com.

Financial or other competing interests: None.

Disclosure forms provided by the authors are available with the full text of this article at jemds.com.

\section{REFERENCES}

[1] Zhu N, Zhang D, Wang W, et al. A novel coronavirus from patients with pneumonia in China, 2019. The New England Journal of Medicine 2020;382:727-33.

[2] Jayaweera M, Perera H, Gunawardana B, et al. Transmission of COVID-19 virus by droplets and aerosols: a critical review on the unresolved dichotomy. Environmental Research 2020;188:109819.

[3] Pulla P. Covid-19: India imposes lockdown for 21 days and cases rise. BMJ 2020.

[4] Hui DS, Zumla A. Severe acute respiratory syndrome: historical, epidemiologic and clinical features. Infectious Disease Clinics 2019;33(4):869-89.

[5] Person B, Sy F, Holton K, et al. Fear and stigma: the epidemic within the SARS outbreak. Emerging Infectious Diseases 2004;10(2):358.

[6] Tam CW, Pang EP, Lam LC, et al. Severe acute respiratory syndrome (SARS) in Hong Kong in 2003: stress and psychological impact among frontline healthcare workers. Psychol Med 2004;34:1197-204.

[7] Chan AO, Huak CY. Psychological impact of the 2003 severe acute respiratory syndrome outbreak on health care workers in a medium size regional general hospital in Singapore. Occup Med (Lond) 2004;54:190-6.

[8] Tran K, Cimon K, Severn M, et al. Aerosol generating procedures and risk of transmission of acute respiratory infections to healthcare workers: a systematic review. PloS One 2012;7(4):e35797.

[9] Peng X, Xu X, Li Y, et al. Transmission routes of 2019$\mathrm{nCoV}$ and controls in dental practice. International Journal of Oral Science 2020;12(1):1-6.

[10] Ather A, Patel B, Ruparel NB, et al. Coronavirus disease 19 (COVID-19): implications for clinical dental care. Journal of Endodontics 2020.

[11] Alharbi A, Alharbi S, Alqaidi S. Guidelines for dental care provision during the COVID-19 pandemic. The Saudi Dental Journal 2020.

[12] Guo ZD, Wang ZY, Zhang SF, et al. Aerosol and surface distribution of severe acute respiratory syndrome coronavirus 2 in hospital wards, Wuhan, China, 2020. Emerg Infect Dis 2020;26(7):10-3201.

[13] Rana U. Elderly suicides in India: an emerging concern during COVID-19 Pandemic. International Psychogeriatrics 2020:1-7.

[14] Roy D, Tripathy S, Kar SK, et al. Study of knowledge, attitude, anxiety \& perceived mental healthcare need in Indian population during COVID-19 pandemic. Asian Journal of Psychiatry 2020:102083.

[15] Ahmed MA, Jouhar R, Ahmed N, et al. Fear and practice modifications among dentists to combat Novel Coronavirus Disease (COVID-19) outbreak. International Journal of Environmental Research and Public Health 2020;17(8):2821.

[16] Qiu J, Shen B, Zhao M, et al. A nationwide survey of psychological distress among Chinese people in the COVID-19 epidemic: implications and policy recommendations. General Psychiatry 2020;33(2)

[17] Jerusalem M, Schwarzer R. Self-efficacy as a resource factor in stress appraisal processes. In: Schwarzer R, ed. Self-efficacy: thought control of action. Washington, DC: Hemisphere 1992:195-213. 
[18] Schwarzer R, Renner B. Social-cognitive predictors of health behavior: action self-efficacy and coping selfefficacy. Health Psychology 2000;19(5):487.

[19] Madhav N, Oppenheim B, Gallivan M, et al. Pandemics: risks, impacts and mitigation. In: Disease control priorities: improving health and reducing poverty. 3rd edn. Washington (DC): The International Bank for Reconstruction and Development 2017.

[20] Bakioğlu F, Korkmaz O, Ercan H. Fear of COVID-19 and Positivity: Mediating Role of Intolerance of Uncertainty, Depression, Anxiety, and Stress. International Journal of Mental Health and Addiction 2020 May 31:1.

[21] Greenberg N, Docherty M, Gnanapragasam S, et al. Managing mental health challenges faced by healthcare workers during covid-19 pandemic. BMJ 2020;368.

[22] Kang L, Ma S, Chen M, et al. Impact on mental health and perceptions of psychological care among medical and nursing staff in Wuhan during the 2019 novel coronavirus disease outbreak: a cross-sectional study. Brain, Behavior and Immunity 2020.

[23] Varshney M, Parel JT, Raizada N, et al. Initial psychological impact of COVID-19 and its correlates in Indian Community: an online (Feel-COVID) survey. PLoS One 2020;15(5):e0233874.

[24] Usher K, Durkin J, Bhullar N. The COVID-19 pandemic and mental health impacts. International Journal of Mental Health Nursing 2020;29(3):315.

[25] Sher L. The impact of the COVID-19 pandemic on suicide rates. QJM: An International Journal of Medicine 2020.
[26] El-Hage, W., et al., (Health professionals facing the coronavirus disease 2019 (COVID-19) pandemic: What are the mental health risks?).Encephale, 2020.

[27] Garcia-Fernandez L, et al. Mental health impact of COVID-19 pandemic on Spanish healthcare workers. Psychological Med 2020:1-6.

[28] Pallavi SK, Rajkumar GC. Professional practice among woman dentist. J Int Soc Prev Community Dent 2011;1(1):14-9.

[29] Jorm AF, Windsor TD, Dear KB, et al. Age group differences in psychological distress: the role of psychosocial risk factors that vary with age. Psychological Medicine 2005;35(9):1253.

[30] Guo H, Zhou Y, Liu X, et al. The impact of the COVID-19 epidemic on the utilization of emergency dental services. Journal of Dental Sciences 2020.

[31] Schönfeld P, Brailovskaia J, Zhang XC, et al. Self-efficacy as a mechanism linking daily stress to mental health in students: a three-wave cross-lagged study. Psychological Reports 2019;122(6):2074-95.

[32] Hobfoll SE. The influence of culture, community and the nested-self in the stress process: advancing conservation of resources theory. Applied Psychology 2001;50(3):337-421.

[33] Hobfoll SE. Conservation of resources: a new attempt at conceptualizing stress. American Psychologist 1989;44(3):513. 